\title{
Developing and comparing optimal and empirical land-use models for the development of an urbanized watershed forest in Taiwan
}

\author{
Yu-Pin Lin ${ }^{\mathrm{a}, *}$, Peter H. Verburg ${ }^{\mathrm{b}}$, Chi-Ru Chang ${ }^{\mathrm{c}}$, Horng-Yng Chen ${ }^{\mathrm{a}}$, Min-Hua Chen ${ }^{\mathrm{a}}$ \\ a Department of Bioenvironmental Systems Engineering, National Taiwan University, No. 1 Sec. 4 Roosevelt Rd., Taipei 106, Taiwan \\ b Department of Environmental Sciences, Wageningen University, PO Box 47, 6700 AA Wageningen, The Netherlands

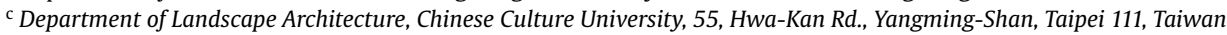

\section{A R T I C L E I N F O}

\section{Article history:}

Received 26 September 2008

Received in revised form 1 May 2009

Accepted 8 May 2009

Available online 4 June 2009

\section{Keywords:}

Optimal land-use pattern

Empirical land-use pattern

Landscape metrics

Runoff

Watershed land-use

\begin{abstract}
A B S T R A C T
The objective of this study is to demonstrate the utility of optimal spatial models for modeling specific spatial patterns to facilitate rational land-use planning of a watershed in northern Taiwan. Optimization was implemented using simulated annealing in a spatial pattern optimization model (OLPSIM), and developments predicted by the drivers of past land-use changes were modeled with the CLUE-s model. The landscapes simulated by the models were then input to a precipitation-runoff model (the Hydrologic Engineering Center's Hydrologic Modeling System; HEC-HMS) to assess the impact of land-use patterns on runoff in the watershed and sub-watershed scales. The results suggest that the three strategies produced very different landscapes under medium intensity scenarios. Specifically, maximizing the size of forest patches caused deforestation of small forest patches, resulting in a large, complex-shaped, dispersed forest; minimizing forest patch shapes resulted in the dissection of large, complex-shaped forests into smaller, simpler-shaped fragments; and land development based on past trends resulted in the aggregation of urbanized land-use in gentler terrains. The results of hydrological simulations suggest that the three land-use strategies differ less in their total hydrological outputs, but more in their distribution of hydrological outputs across different sub-watersheds. Investigating more spatially explicit hydrologic impacts of urbanization at the sub-basin scale may provide additional information that would help decision-makers evaluate proposed land-use policies more thoroughly.
\end{abstract}

(c) 2009 Elsevier B.V. All rights reserved.

\section{Introduction}

Spatial land-use patterns affect the ecological, physical and socio-economic processes of a region in various ways (Brookes, 2001; Forman, 1995; Turner et al., 2001). Therefore, a thorough understanding of land-use dynamics is necessary to predict future changes accurately, and to facilitate the development of sustainable management practices designed to preserve essential landscape functions (Hietel et al., 2004; Lin et al., 2007a). Modeling land-use changes helps inform policymakers of possible future conditions under different scenarios (Koomen and Stillwell, 2007). Although there are many types of models for simulating future land-use, they all rely on a limited number of theories and methods (Koomen and Stillwell, 2007; Verburg and Veldkamp, 2005). Stochastic models, optimization models, dynamic process-based simulation models and empirical-statistical models are examples of approaches that

\footnotetext{
* Corresponding author. Tel.: +886 2 33663464; fax: +886223686980.

E-mail addresses: yplin@ntu.edu.tw (Y.-P. Lin), Peter.Verburg@wur.nl (P.H. Verburg), crchang@faculty.pccu.edu.tw (C.-R. Chang), b93602022@ntu.edu.tw (H.-Y. Chen), meanwhy@yahoo.com.tw (M.-H. Chen).
}

have been used to explore land-use changes. Each type of model has its own potential and constraints with respect to the requirements and expectations of land-use planners and policy makers (Castella et al., 2007).

Besides models for exploring possible land-use changes under plausible scenarios in the near-future, policymakers also need tools that can determine the optimal land-use configuration in terms of costs and effects (Loonen et al., 2007). Given a set of prior conditions, criteria, and decision variables, the optimal configuration can be calculated by applying mathematical optimization techniques (Koomen and Stillwell, 2007). A land-use model based spatial pattern optimization can be a complementary tool for supporting normative landscape design (Duh and Brown, 2005; Loonen et al., 2007) and land-use planning. For spatial pattern optimization, the purpose of the model is to generate spatial realizations that take account of specific goals, instead of reproducing a particular landscape (Duh and Brown, 2005). This is a powerful method for exploring the potential of a given area to improve the spatial coherence of land-use functions (Loonen et al., 2007), such as issues of habitat suitability (Holzkämper et al., 2006; Seppelt and Voinov, 2002; Westphal et al., 2007), agricultural sustainability (Mandal, 2007; Zander and Kächele, 1999) and optimal forest management 
(Baskent and Jordan, 2002; Ducheyne et al., 2006; Öhman and Lämås, 2005).

In both theory and practice, it is of paramount importance that questions of land-use pattern optimization (Wu and Hobbs, 2002) are based on understanding of the influence of land-use patterns on landscape functioning. For instance, patch configuration is an important criterion in habitat design as well as in applications like watershed management, forestry, the setting of electoral district boundaries, and local authority planning (Brookes, 2001). Patch size is important for studying population viability (Brookes, 2001; Dramstad et al., 1996; Forman, 1995; Turner et al., 2001), and ecological diversity (Brookes, 2001; Dramstad et al., 1996; Hof and Flather, 2007; Probst and Weinrich, 1993). In particular, large patches have been identified important to the maintenance of populations and biodiversity (Robinson et al., 1992; Dramstad et al., 1996), and have been shown to be equivalent or better at protecting various biodiversity components than an umbrellaspecies approach (Poiani et al., 2002). Shape affects the role of patches as corridors (Dramstad et al., 1996; Fahrig and Merriam, 1985; Selman and Doar, 1992) or habitats (Dramstad et al., 1996; Laurance, 1991) and the amount of interaction with surrounding areas (Turner et al., 2001). In particular, compact shapes provide for more core area (Baskent and Jordan, 1995), and were found beneficial to species negatively impacted by landscape fragmentation (Villard et al., 1999). Landscape metrics may be useful as a first approximation of broad-level landscape patterns and processes, and for characterizing the differences between planned and design alternatives. They may also be appropriate for land-use planning and design (Jongman, 1999; Lin et al., 2007a). For example, landscape metrics can be applied in a spatial pattern optimization model to produce a land-use pattern that takes account of the specific goals of optimal land-use planning and design in a watershed.

In contrast to spatial optimization models, empirical-statistical models have been developed to identify the factors that influence land-use changes, and predict future land-use change patterns upon changes in driving factors as specified in scenarios (Verburg et al., 2006). Multiple linear regression or logit models are frequently used for this purpose. A well-known example of an empirical-statistical model is the Conversion of Land-use and its Effects model (CLUE-s) that combines empirically quantified relationships between land-use and its driving factors with dynamic modeling of competition between land-uses (Lin et al., 2007a,b). The CLUE-s model does not provide optimal solutions, but projects plausible developments instead (Castella et al., 2007). Recently, the CLUE-s model has been successfully applied in simulating landuse changes based on different spatial and non-spatial policies (Verburg et al., 2006; Castella and Verburg, 2007; Castella et al., 2007; Lesschen et al., 2007; Lin et al., 2007a,b; Overmars et al., 2007).

The objective of this study is to show the utility of optimizing for specific spatial patterns of ecological relevance through the use of the optimal spatial model (OLPSIM) for rational watershed land-use planning. This is achieved by comparing simulated land-use patterns and hydrological outputs resulting from optimal strategy scenarios versus an empirical trend scenario. The resulting maximum forest patch scenarios and minimum patch shape scenarios as suggested by the OLPSIM model were then compared with the land-use scenarios predicted by the empirically based CLUE-s model under similar land-use intensity. The CLUE-s model predicted future land-use scenarios based on driving factors of past land-use changes without the influence of predefined objectives. All resulting land-use patterns were then input to a precipitationrunoff hydrological model (the Hydrologic Engineering Center's Hydrologic Modeling System; HEC-HMS) to assess their impact on runoff.

\section{Methods and materials}

In this study, we used simulated annealing (SA) to solve spatial pattern optimization problems in the OLPSIM model. The optimization process involved two management objectives: (1) to spatially allocate development areas that would result in the largest mean forest patch size; or (2) to allocate development areas that would result in the most compact shape of forest patches. The CLUE-s model, on contrary, was based on an empirical analysis of past landuse change, predicting future land-use under the assumption of constant driving forces. Both OLPSIM and the CLUE-s models were tested under different land-use intensities and development strategies and restricted by regulations explained in the "study area" section. Finally, the results of all simulations were compared using landscape metrics of the forest patches and hydrological outputs from the landscape were estimated using HEC-HMS.

\subsection{Study area and data}

The Wu-Tu watershed is a section of the Keelung River Basin, and is located upstream of the Taipei metropolitan area close to Keelung Harbor in northern Taiwan (Fig. 1). It covers approximately $204.00 \mathrm{~km}^{2}$ of mostly hilly terrain, with a mean elevation of $242.00 \mathrm{~m}$. Land-use maps for 1999 were generated and digitized by the Soil and Water Conservation Bureau Council of Agriculture, Taiwan, based on 1:5000 aerial photographs taken in 1999. Based on the definitions of land-use types provided by the Construction and Planning Agency of the Ministry of Interior, we reclassified the land-use into five main categories, showing the current land-use of the area as $1.00 \%$ agricultural land, $83.00 \%$ forest, $6.00 \%$ built up area, $3.00 \%$ grassland, and $7.00 \%$ water bodies.

Given its hilly terrain and upstream position to the Taipei metropolitan area, half the watershed is ecologically sensitive. Approximately 9600 ha (63\%) of the currently forested area is protected from development by safe drinking water, slope protection, and forest regulations (Fig. 1(B)). Development pressure, however, have increased rapidly in the past two decades due to the expansion of both the Taipei metropolitan area and Keelung City, and the need for labor in Keelung Harbor. Since 1997, the average annual population growth rate has been approximately 1.1\% (Lin et al., 2007a) and continues to grow, mounting pressure to the remaining undeveloped forested lands. The watershed can be divided into nine sub-watersheds (Fig. 1(C)). Sub-watersheds 8 and 9 are in the less developed upstream regions, sub-watersheds 1, 3, 4, 5, 6 and 7 are in the more urbanized downstream regions, and sub-watershed 2 is in the midstream regions.

\subsection{Development scenarios}

To evaluate the effects of land-use patterns optimized for maximum forest patch size and minimum forest patch shape, a range of different development intensities and two planning strategies were tested. For development intensities, we tested a range of land-use intensity scenarios in which the proportion of forest to built-up conversion increased in increments of $5 \%$ up till a total of $35 \%$ of forest area converted to built-up, approaching the maximum area not restricted by current laws and regulations. The two different planning strategies involved 1) an evolving scenario in which a $5 \%$ conversion was considered and simulated for each time step until a total of $35 \%$ forest land has been converted to built-up (labeled "sequential" in the following discussion), and 2) a onetime planning for the conversion of a targeted percentage (labeled "simultaneous"), which may later be implemented gradually across a long time span. The "sequential" optimization was performed with an optimal solution for each time step, and the resulting landuse pattern was taken as the initial land-use pattern for the next 


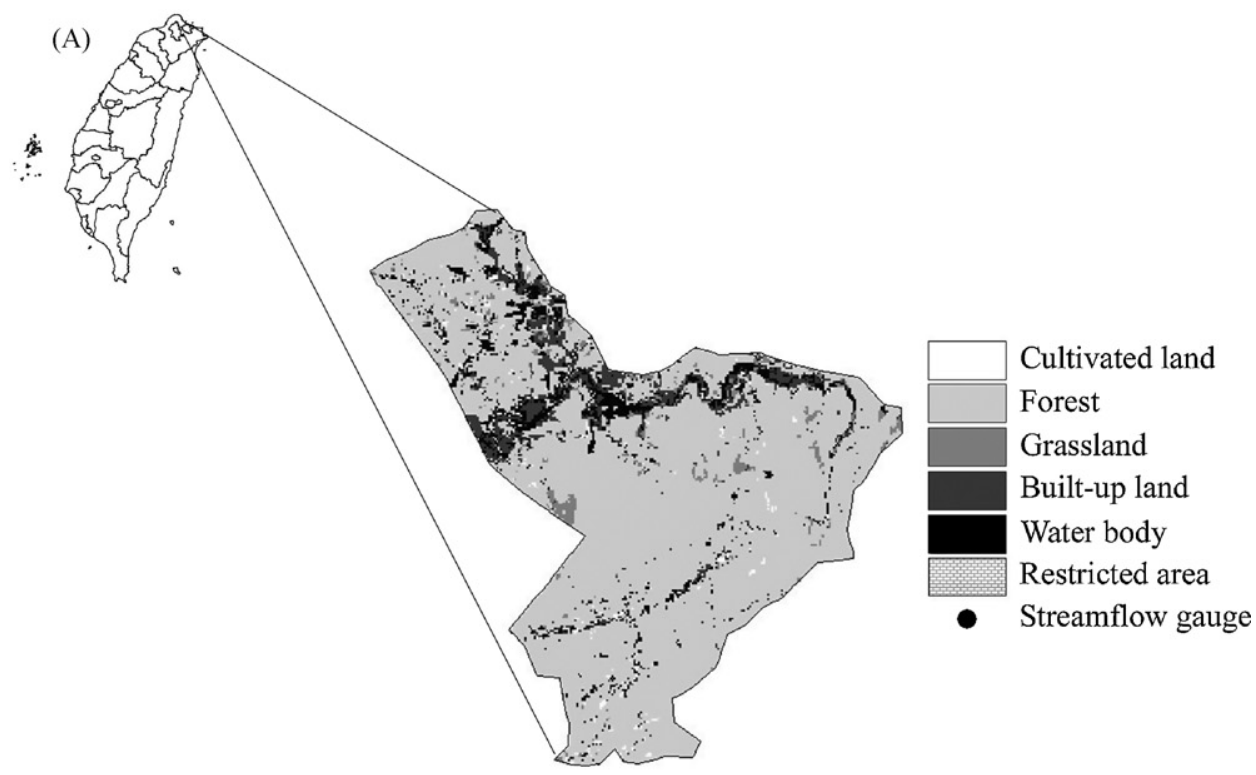

(B)
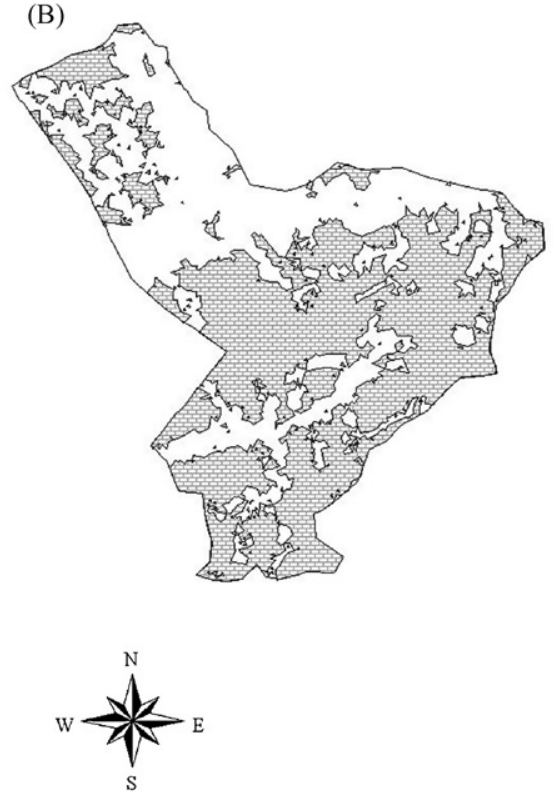

$\begin{array}{lll}5 & 0 \quad 5 & \text { Kilometers }\end{array}$
(C)

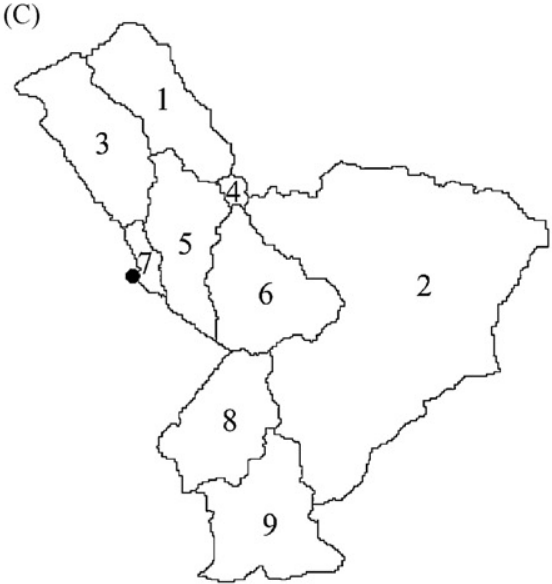

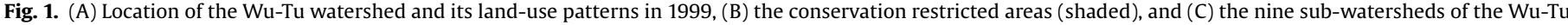
watershed.

step, thus basing each optimization on the resulting landscapes from preceding optimizations.

\subsection{CLUE-s model}

In this study, we used the CLUE-s model to simulate land-use patterns under seven development intensities, in which $5 \%, 10 \%$, $15 \%, 20 \%, 30 \%$ and $35 \%$ of forested areas were converted into built-up areas. The model allocates land-use changes by an iterative procedure that utilizes probability maps, decision rules specifying which transitions are possible and/or allowed and a series of conversion elasticities accounting for the current land-use maps. At the start of the iteration procedure the iteration variables are given an equal value for all land-use types. Land-use is allocated by assigning the land-use with the highest total probability to the considered grid cell. The total probability is the sum of the probability calculated based on the location characteristics, the conversion elasticity and the iteration variable. The value of the iteration variable is increased for land-use types where the allocated area is smaller than the demanded area. The iterative process continues until the aggregated cover of all grid cells is equal to the land-use demands. The probability is expressed by the following logit model (Lin et al., 2007a):

$\log \left(\frac{P_{i}}{1-P_{i}}\right)=\beta_{0}+\beta_{1} X_{1, i}+\beta_{2} X_{2, i}+\cdots+\beta_{n} X_{n, i}$,

where $P_{i}$ denotes the probability of a grid cell being allocated to a certain type of land-use $i, X_{n, i}$ represents driving factor $n$, and $\beta_{n}$ is the coefficient of driving factor $n$ in the logistic model. 
Table 1

Logistics regression model for land-use types.

\begin{tabular}{|c|c|c|c|c|}
\hline Variable & Agriculture & Forest & Built-up & Grass \\
\hline Altitude (Dtm) & 0.0016 & 0.0013 & - & -0.0046 \\
\hline Slope & -0.0316 & 0.0588 & -0.0149 & -0.0278 \\
\hline Population density (PopD) & -0.0001 & -0.0001 & 0.0000 & - \\
\hline Distance to major roads (Droad) & -0.0015 & -0.0002 & - & 0.0011 \\
\hline Distance to rivers (Driver) & - & 0.0002 & - & -0.0003 \\
\hline Distance to built-up areas (Dbuilt) & -0.0012 & 0.0065 & -0.0483 & 0.0023 \\
\hline Distance to urban planning areas (Dzone) & -0.0003 & - & - & -0.0001 \\
\hline Soil's drainage (Odr) & - & - & - & - \\
\hline Soil erosion coefficient (SoilK) & 2.1724 & 4.8862 & -2.3359 & - \\
\hline Constant & -3.3421 & -1.3567 & 1.0928 & -1.8798 \\
\hline $\mathrm{ROC}$ & 0.730 & 0.874 & 0.973 & 0.76 \\
\hline
\end{tabular}

ROC represents the relative operating characteristic value. -: not significant and not included in model at 0.05 significant level.

According to Lin et al. (2007a), the factors that drive land-use change in the $\mathrm{Wu}-\mathrm{Tu}$ watershed include the altitude $(\mathrm{m})$, slope, distance from the river, soil erosion coefficient, soil drainage, distance from major roads, distance from a built-up area, distance from urban planning areas, and population density. In addition, we used the relative operating characteristic (ROC) to assess the goodness-of-fit of the model's logistic regressions. We performed forward stepwise logistic regression and ROC analysis using the Sta- tistical Package for the Social Sciences (SPSS) for Windows (SPSS Inc., IL, USA). Forested areas protected by laws and regulations were exempt from development by both the OLPSIM and CLUE-s models (Fig. 1(B)). The ROC values for the logistic models ranged between 0.73 and 0.97 , indicating that the models with driving factors were capable of representing the suitability of locations for all land-use types (Table 1). The probability maps of forest and other land-use types are shown in Fig. 2.
(A)

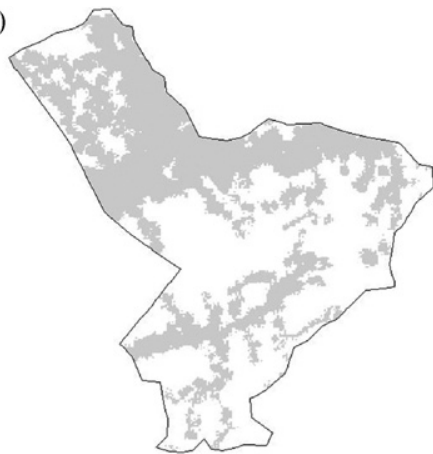

(C)

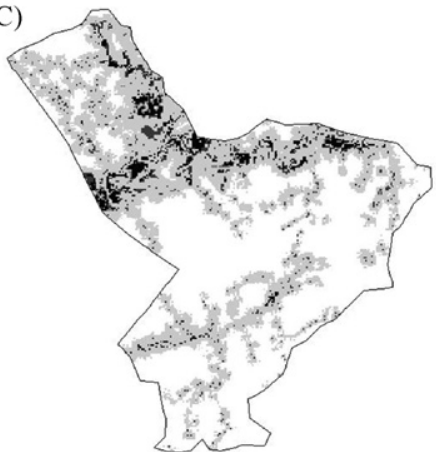

(E)

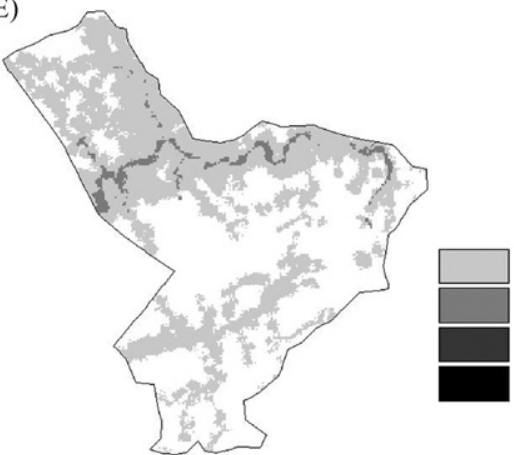

(B)

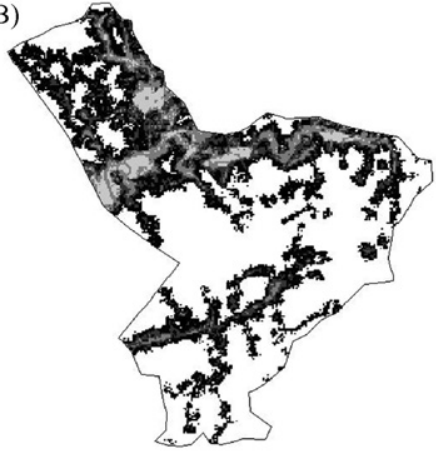

(D)

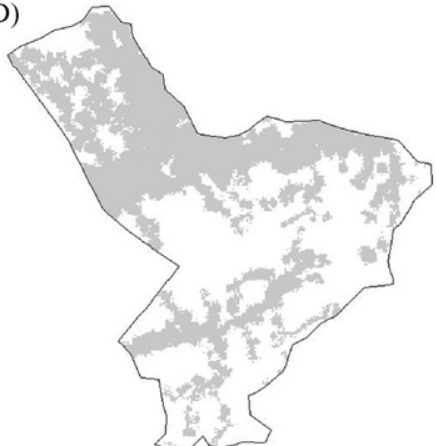

$0.00-0.25$

$0.25-0.50$

$0.50-0.75$

$0.75-1.00$

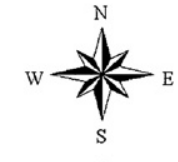

$5 \quad 0 \quad 5$ Kilometers

Fig. 2. Probability maps of (A) agriculture land, (B) forest, (C) built-up, (D) grassland, and (E) water. 


\subsection{Optimal land-use pattern model and optimization goals}

Simulated annealing SA avoids entrapment in local optima by also accepting solutions that result in worse objective function values (Duh and Brown, 2005). The acceptability of the results is based on a probabilistic acceptance criterion controlled by the annealing temperature (Floudas and Paradalos, 2001). A cooling schedule, which starts at a high temperature and decreases toward zero as the search progresses, allows SA to freely explore the solution space at the beginning of an optimization process; and fully exploit the most promising region in the solution space as the temperature drops.

Our study had two objectives: (1) to optimize the maximum mean patch size (MPS) of forest patches; and (2) to optimize the minimum mean patch shape index (MSI) of forest patches. The first objective function of the optimization model is defined as follows:

$\operatorname{Max} \quad \mathrm{MPS}=\frac{\sum_{j=1}^{n_{i}} a_{j}}{n}$

subject to $D=A-\sum_{j=1}^{n_{i}} a_{j}$,

where $a_{j}$ is the $j$ th patch area $\left(\mathrm{m}^{2}\right)$ of a forest patch, $n$ is the number of forest patches, $D$ is the size of the developed area $(5.00 \%, 10.00 \%$, $15.00 \%, 20.00 \%, 25.00 \%, 30.00 \%$ and $35.00 \%$ ), and $A$ is the area of the study watershed.

The second objective function is defined as

Min $\quad$ MSI $=\frac{\sum_{j=1}^{n_{i}}\left(0.25 p_{i j} / \sqrt{a_{i j}}\right)}{n}$

subject to $D=A-\sum_{j=1}^{n_{i}} a_{j}$,

where $p_{i j}$ is the $j$ th patch perimeter $(\mathrm{m})$ of land-use class $i$.

The steps of the optimization procedure are as follows: (1) select an objective function (the maximum mean patch size or the minimum mean patch shape) and set the initial temperature; (2) set the existing land-use pattern as the initial land-use; (3) randomly select cells from the forested areas for development, except protected areas until the developed area equals a predetermined development size $D$; (4) calculate the value of the objective function after the development; (5) define the neighbors of the current solution (i.e., alternative solutions) and evaluate the objective values of the neighbor solutions; (6) determine if the current solution is the final one via the acceptance probability function, which considers the current temperature as well as the differences between the objective value of the current solution and the values of its neighbor solutions; (7) if the current solution is considered inadequate, return to step (3) for further iterations. Otherwise, the recorded solution is taken as the final optimal solution.

\subsection{Landscape metrics}

Landscape ecological studies provide many useful conceptual and analytical tools to bridge the gap between planning and ecology (Leitão et al., 2006). Of these, landscape metrics are particularly promising because they are readily applicable, and many of these are responsive and indicative of the different processes of fragmentation. For example, fragmentation often results in attrition and dissection of habitats, resulting in an increase in number of patches (NP) and a decrease in mean patch size (MPS) as large patches are broken up into two or more smaller pieces. Fragmentation also often results in higher interspersion among patches, creating longer edges, stronger edge effects and increased transitional zones. Such increase in edges can be indicated by total edge (TE). Independent of fragmentation, patch shapes may also affect the well-being of edge-sensitive species, as more complex shapes mean more edges and less core area. Mean shape index (MSI) and mean patch fractal dimension (MPFD) can be used as indicators of shape complexity. Another aspect of fragmentation is the isolation of patches, which inhibits colonization processes and negatively affects processes maintaining metapopulations and biodiversity. Mean nearest neighbor distance (MNN) can be used as an indicator of dispersion and thus probability of among patch movements. Therefore, we used six landscape indices, namely number of patches (NP), mean patch size (MPS), mean shape index (MSI), total edge (TE), mean patch fractal dimension (MPFD), and mean nearest neighbor (MNN) to present the forest configuration in the $\mathrm{Wu}-\mathrm{Tu}$ watershed. The landscape metrics for the forest patches were calculated using the Patch Analyst (Elkie et al., 1999) in GIS software ArcView 3.2a. Detailed descriptions of the above metrics can be found in McGarigal and Marks (1995).

The metrics used in this study were calculated as follows:

$\mathrm{NP}=n_{f}$,

where $n_{f}$ is the number of patches in land-use class forest.

$\mathrm{MPS}=\frac{1}{n_{f}} \sum_{j=1}^{n_{f}} a_{j}$,

where $a_{j}$ is the area $\left(\mathrm{m}^{2}\right)$ of the $j$ th patch of land-use class forest.

MSI $=\frac{\sum_{j=1}^{n_{f}}\left(0.25 p_{j} / \sqrt{a_{j}}\right)}{n_{f}}$,

$\mathrm{MPFD}=\frac{\sum_{j=1}^{n_{f}}\left(2 \ln \left(0.25 p_{j}\right) / \ln a_{j}\right)}{n_{f}}$,

where $p_{j}$ is the perimeter $(\mathrm{m})$ of the $j$ th patch of land-use class forest.

$\mathrm{MNN}=\frac{\sum_{j=1}^{n_{f}} h_{j}}{n_{f}}$,

where $h_{j}$ is the distance $(\mathrm{m})$ from the $j$ th patch of forest to the nearest neighboring patch of forest based on the edge-to-edge distance.

\subsection{HEC-HMS model}

In this study, we used a hydrological model, HEC-HMS, to calculate the surface runoff from the resulting landscapes. HECHMS, developed by United States Army Corps of Engineers (USACE) (McColl and Aggett, 2007), is designed to simulate the precipitation-runoff processes of dendritic watershed systems (Knebl et al., 2005). Similar to Knebl et al. (2005) and McColl and Aggett (2007), evapotranspiration (ET) losses were considered negligible given the intensity of storms and our assumption that the ET volume is negligible compared to the runoff volume. Moreover, the following routines were incorporated into the HEC-HMS model: (1) the initial deficit constant loss infiltration routine, (2) kinematic wave routing for both overland and channel flow, and (3) exponential recession baseflow (subsurface flow). Nine sub-watersheds were delineated by Geospatial Hydrologic Modeling Extension (HEC-GeoHMS) model, as shown in Fig. 1(C). HEC-GeoHMS executes terrain pre-processing by utilizing the surface topography as the origin of the stream network, and delineates sub-basins from the network and local topography (Knebl et al., 2005).

In HEC-HMS, runoff is calculated by the following equations:

$Q=\frac{(P-0.2 S)^{2}}{(P+0.8 S)}$
$S=\left(\frac{25,400}{C N}\right)-254$, 
where $Q$ denotes the runoff $(\mathrm{cm}), P$ denotes the rainfall $(\mathrm{cm}), S$ is the potential maximum retention, and $\mathrm{CN}$ is the runoff curve number.

The Kinematic wave method assumes that sub-areas are large planes with a main channel that drains to the sub-area outlet (Beighley et al., 2003). The main channel receives lateral inflow from the overland flow planes, where the overland flow is approximated as a wide rectangular channel flow (Beighley et al., 2003). For subareas with upstream inflow, the main channel routes the upstream flow as well as the lateral inflow to the sub-area outlet (Beighley et
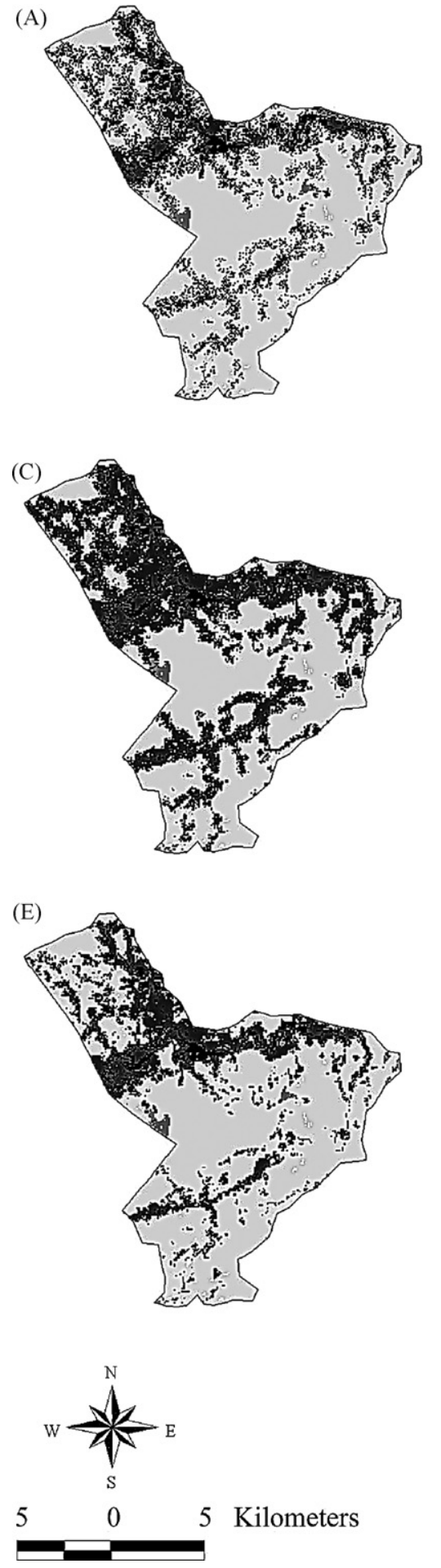

al., 2003). Further details about the Kinematic wave method can be found in the technical reference manual (HEC, 2000). The recession model defines the relationship of $Q$ the baseflow at time $t$, as an initial value:

$Q=Q_{0} k^{t}$

where $Q_{0}$ is the initial baseflow (at time zero), and $k$ is an exponential decay constant.

(B)

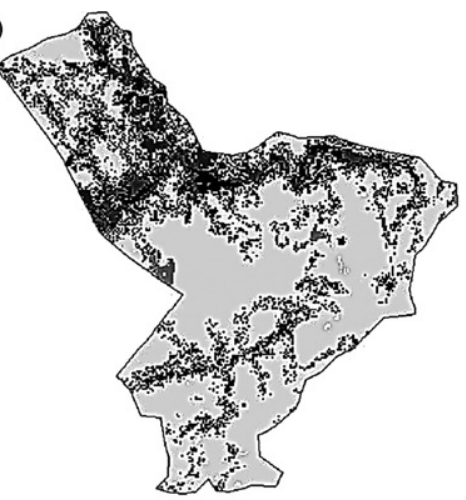

(D)

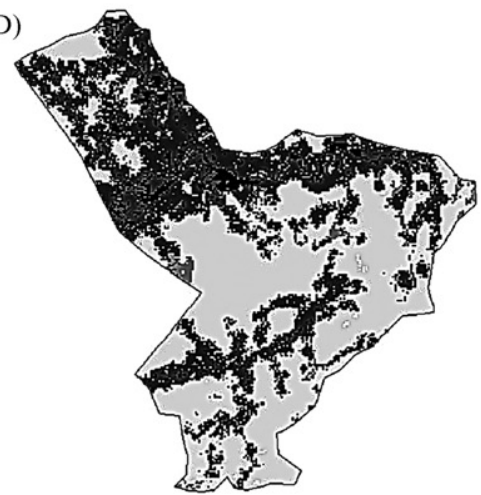

(F)

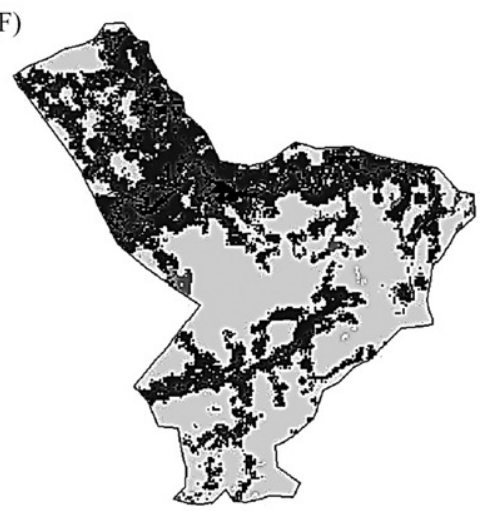

Cultivated land

Forest

Grassland

Built-up land

Water body

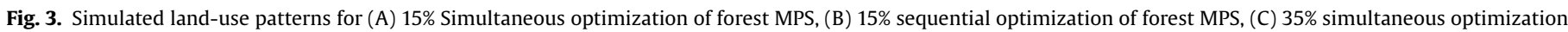
of forest MSI, (D) 35\% sequential optimization of forest MSI, (E) 15\% development of CLUE-s model, and (F) 35\% development of CLUE-s model. 
We calculated the coefficient of efficiency $(E)$ as a measure of goodness-of-fit to assess the model's performance in the watershed and at the outlet. The value of $E$ can be within a range from minus infinity (a poor model) to 1.0 (a perfect model).

$E=1.0-\frac{\sum\left(O_{i}-P_{i}\right)^{2}}{\sum\left(O_{i}-\bar{O}\right)^{2}}$,

where $O$ represents observed values, $P$ represents predicted values, and $\bar{O}$ denotes the mean for the entire evaluation period (McColl and Aggett, 2007).

In 1999, two storm events occurred in the study watershed on October 3 and December 16, respectively. After the storms, rainfall data from four rainfall gauges and runoff data from one stream gauge (Fig. 1) was collected for calibration, validation and an impact assessment of simulated land-use patterns on runoff using the HECHMS model. The data from the first storm were used to calibrate the model. Then, the data from the second storm were used to validate the model.

\section{Results}

\subsection{Land-use patterns optimized for forest patch size and shape}

Fig. 3 presents the landscapes that are obtained by maximizing the size of the forest patches and minimizing their shape in the developments along the north along the stream are very similar to those in the southern parts of the study watershed (Fig. 1(B)). To maximize forest patch sizes (Fig. 3(A) and (B)), new developments tend to be more scattered over the map than expected based on the results of the empirically based CLUE-s model under a similar land-use intensity (15.00\%, Fig. 3(E)). The optimal scenario for minimizing the forest patches (Fig. 3(C) and (D)), includes development patterns that are very similar to those of the empirically based CLUE-s model under a similar land-use intensity (35.00\%, Fig. 3(F)).

Fig. 4 shows changes in forest class-level metrics with an increase in intensity of conversion of the forest to built-up areas. Of all forest development scenarios, the forest MPS value was highest when $15.00 \%$ of the forest was removed. In this scenario, the optimal MPS value was 2.30 times greater than in the case of no forest
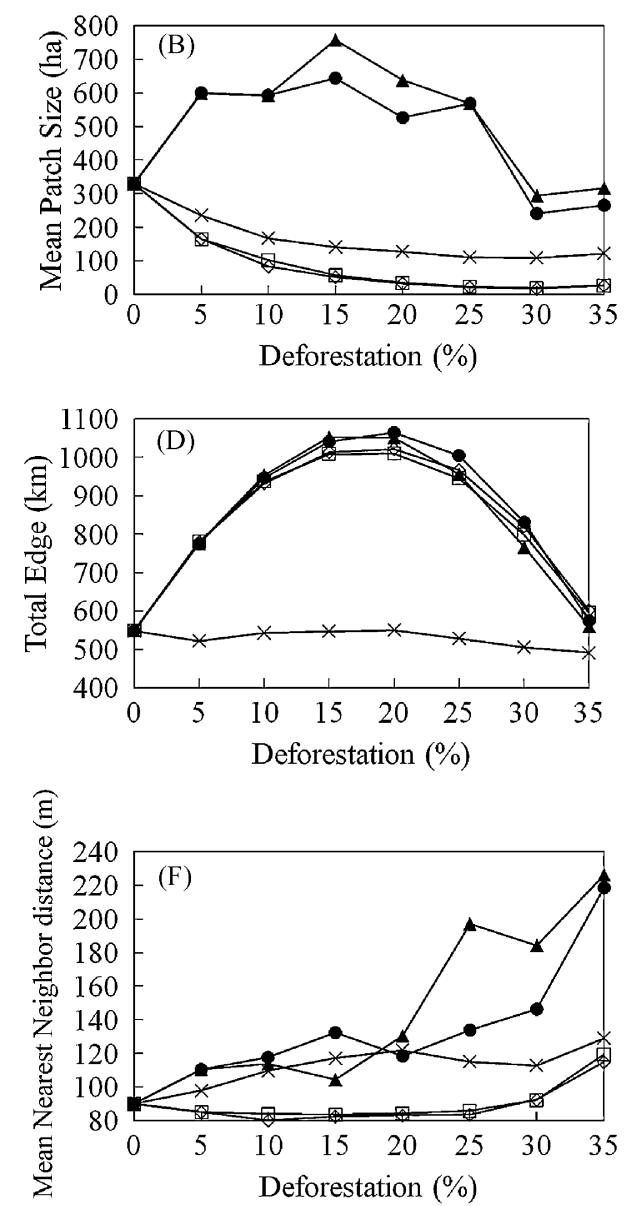
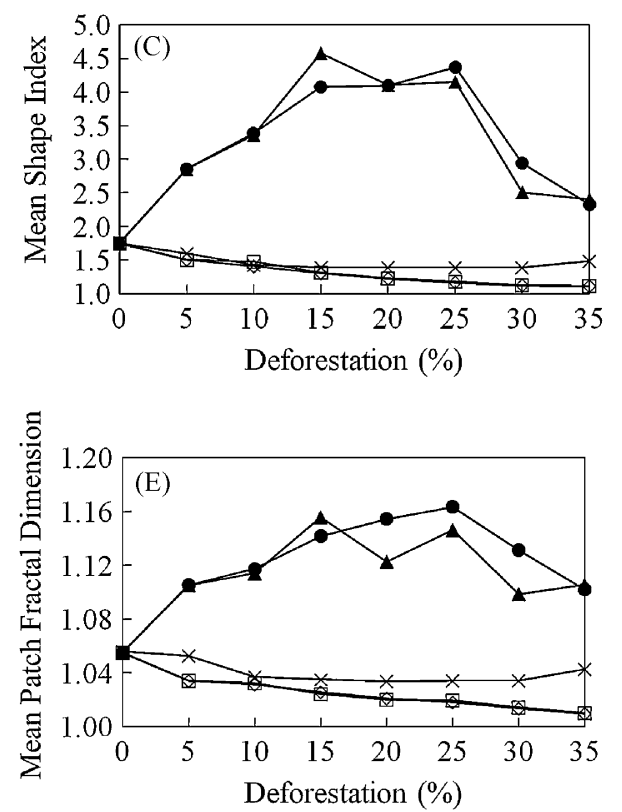

Simultaneous strategies for the optimal MPS values

Sequential strategies for the optimal MPS values

* Sequential strategies for the CLUE-s values

Simultaneous strategies for the optimal MSI values

Sequential strategies for the optimal MSI values

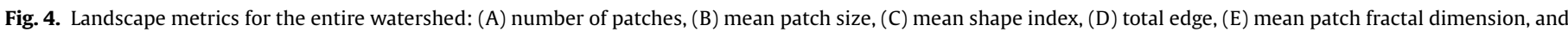
(F) mean nearest neighbor distance. 
development. Under a given planning policy, the mean patch size, mean shape index, mean fractal perimeter dimension and mean nearest neighbor values were always greater under the simultaneous consideration strategy than under the sequential consideration strategy for the forest-removal intensity (Fig. 4). Additionally, as presented in Fig. 4, the optimal forest patches with maximized mean patch size were larger, more complex in shape, and fewer in number than the original forest patches (in 1999) over the entire the watershed, according to all forest removal simulations.

Of all of the optimal forest development scenarios, the MSI value was lowest when $35.00 \%$ of the forest was removed. The values of the mean patch size, mean shape index, mean fractal perimeter dimension and mean nearest neighbor under "sequential" and "simultaneous" considerations of forest removal were similar (Fig. 4). Additionally, the optimally shaped forest patches with minimized mean patch shape index became more compact and greater in number than the original forest patches (in 1999) (Fig. 4).

\subsection{Empirical land-use patterns}

Fig. 4 also presents the landscape metrics for forest patches that were simulated using the CLUE-s model under identical forest removal intensities. The values of MPS and MSI for land-use patterns derived by CLUE-s gradually decrease as the percentage removal of the forest increases. The simulated MPS values are always less than the initial MPS value revealing that without active land-use planning, the MPS value is unlikely to be maximized. The MSI land-use values of CLUE-s were minimal with $15.00 \%, 20.00 \%$, $25.00 \%$ and $30.00 \%$ forest development. The forest patches simulated using the CLUE-s model were slightly more compact and greater in number than the original forest patches. In the simulation of $10.00 \%$ conversion, the Mean Shape Index of the CLUE-s results equaled the shape index minimized by the optimization model.

\subsection{Runoff under empirical and optimized land-use patterns}

Fig. 5 shows the results of HEC-HMS calibration and validation. The coefficient of efficiency is 0.86 . Moreover, the $R^{2}$ values of the linear regression model of the hourly observed stream flows versus the simulated stream flows during the second storm, with a slope of 0.65 , was 0.58 . The results of the linear regression models were significant at the $p \leq 0.01$ level. Fig. 6 shows the hydrograph of streamflows of selected OLPSIM and CLUE-s land-use simulations based on the storm event on December 16, 1999. In the case of optimal MPS, the removal of $15.00 \%$ of the forest increased the runoff volume by $5.76-5.77 \%$ and the peak flow by $4.78-4.83 \%$ over the corresponding values for the 1999 land-use patterns over the entire watershed. In the case of optimal MSI, the removal of 35\% of the forest increased the runoff volume by $13.31-13.36 \%$ and the peak flow by $13.12-13.25 \%$ over the corresponding values for the 1999 land-use patterns of over the entire watershed. For $15.00 \%$ forest development, the CLUE-s land-use patterns increased the runoff volume by $6.09 \%$ and the peak flow by $4.74 \%$ over those of the 1999 land-use patterns over the entire watershed. For 35.0\% forest development, the CLUE-s land-use patterns increased the runoff volume by $13.41 \%$ and the peak flow by $13.38 \%$ over those of the 1999 land-use patterns over the entire watershed.

Fig. 7 shows the hydrograph of the streamflow in the subwatersheds in all OLPSIM and CLUE-S land-use cases based on the storm event in December 1999. The peak flow and runoff volume increased in all cases, as shown in Tables 2 and 3. For the $15.00 \%$ forest development policy with maximized MPS (Table 2), sequentially maximizing MPS and CLUE-s yielded highest increases in peak flows of $21.01 \%$ in sub-watershed 3, 20.74\% in sub-watershed and $22.34 \%$ in sub-watershed 5 , respectively. The increases in peak flows
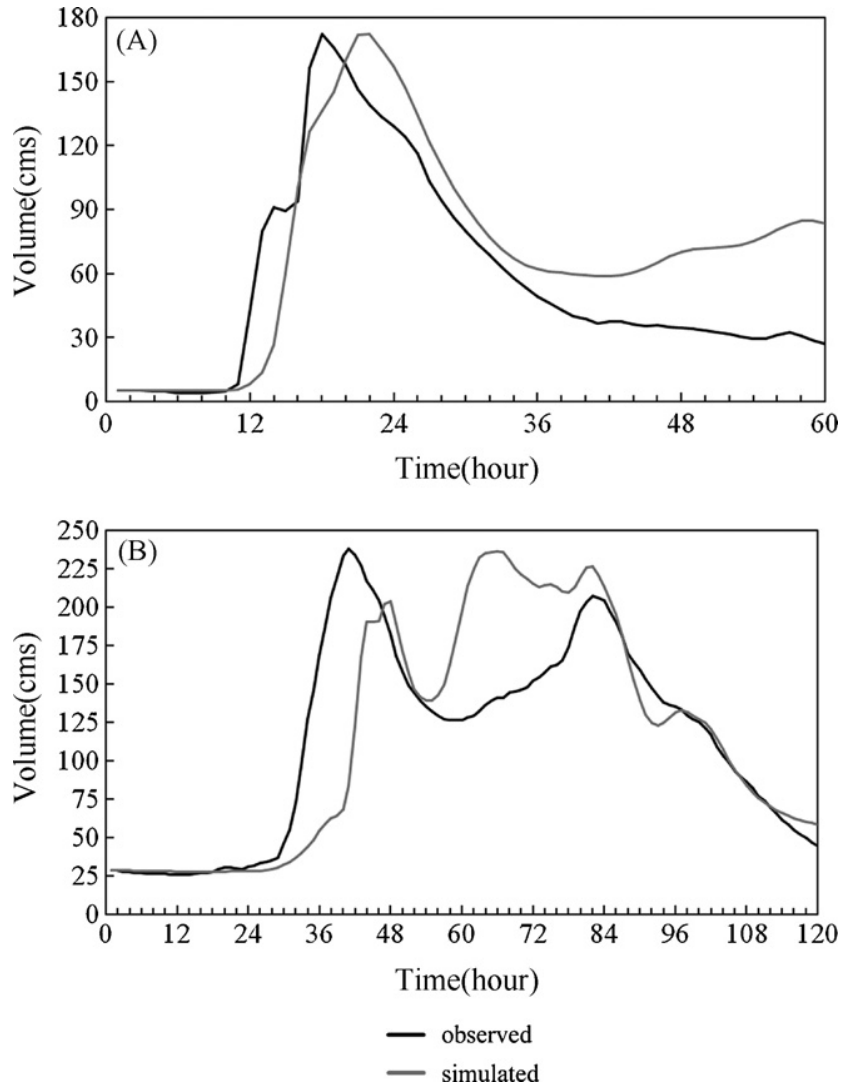

Fig. 5. Stream flows of the HEC-HMS results for (A) calibration, and (B) validation.

in sub-watersheds 3, 5 and 8 all exceeded $15.00 \%$ when MPS was maximized simultaneously or sequentially. The increases in peak flows in sub-watersheds $1,3,5,7$ and 8 exceeded $15.00 \%$ in the case of $15.00 \%$ forest development under CLUE-s. Moreover, the largest increases in runoff volumes were $8.89 \%$ in sub-watershed $3,8.78 \%$ in sub-watershed 3 , and $12.17 \%$ in sub-watershed 7 in the simultaneous maximization of MPS, the sequential maximization of MPS and CLUE-s, respectively. The increases in runoff volumes in all sub-watersheds were less than $10.00 \%$ whenever MPS was simultaneously or sequentially maximized. For the $15.00 \%$ forest
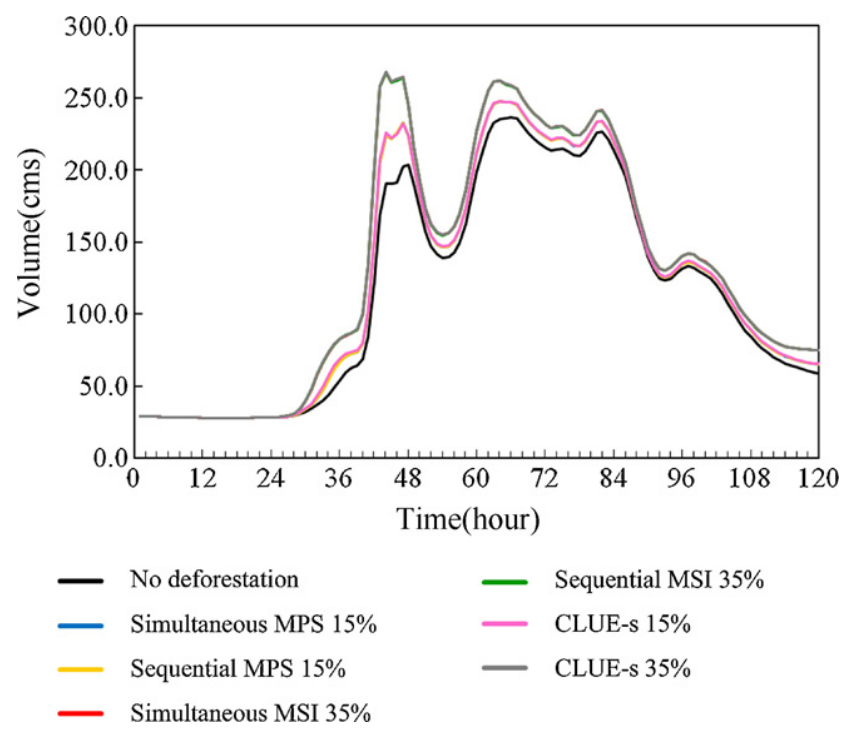

Fig. 6. Simulated stream flows of different development strategies and policies for the entire watershed. 

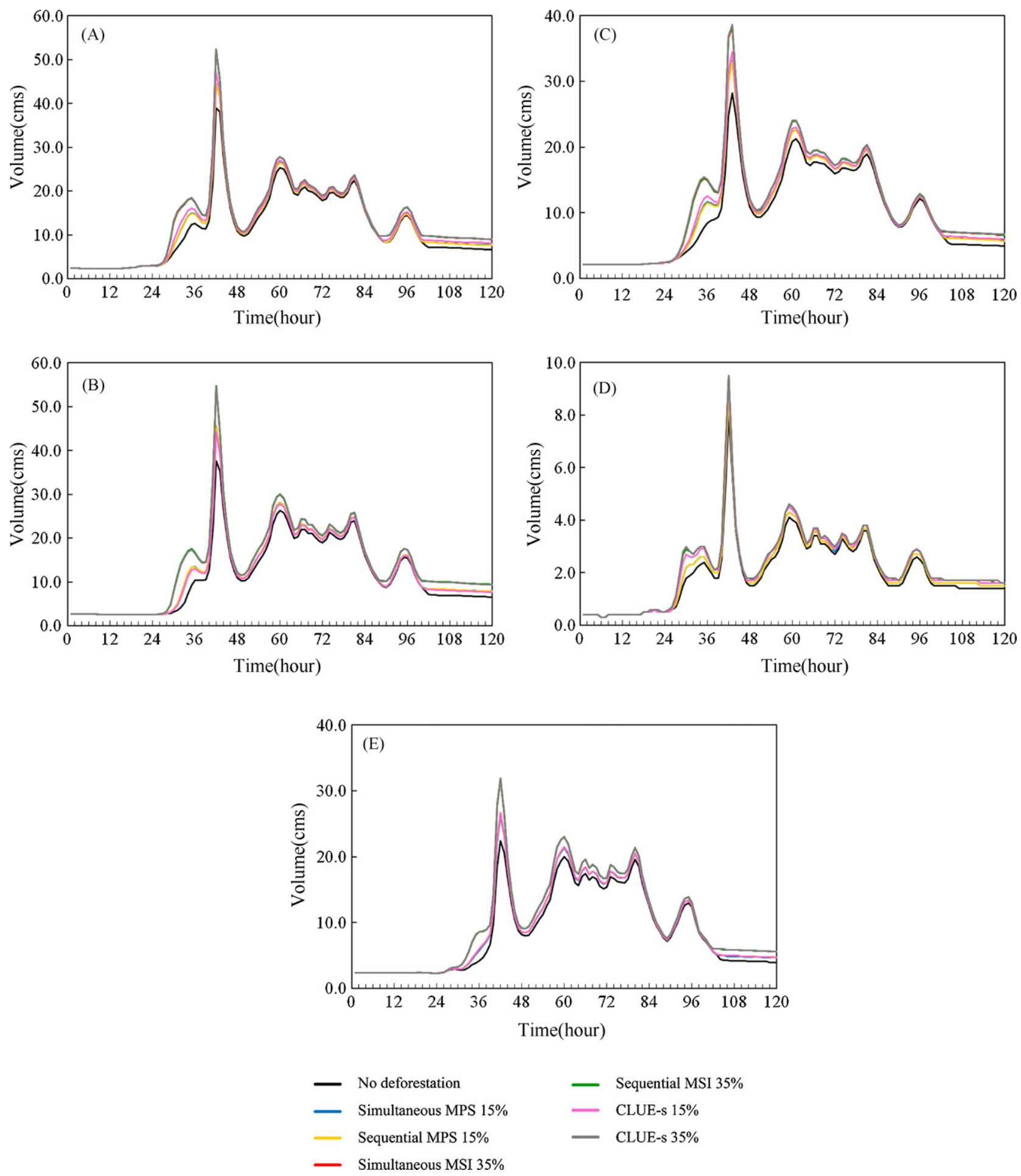

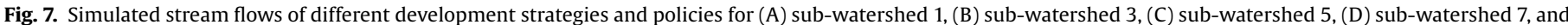
(E) sub-watershed 8.

development scenario in the CLUE-s model, the increases in runoff volumes in sub-watersheds 5 and 7 exceeded $10.00 \%$, and those in sub-watersheds 1 and 4 exceeded $9.80 \%$.

For the $35 \%$ forest development policy (Table 3), the greatest increases in peak flows were $45.21 \%, 45.48 \%$ and $44.68 \%$ in sub-watershed 3 , in the cases of simultaneously minimizing MSI, sequentially minimizing MSI and CLUE-s, respectively. The increases in peak flows in all sub-watersheds were greater than
$15.00 \%$ in the cases of simultaneously and sequentially minimizing MSI, except in sub-watershed 4 . For the $35.00 \%$ forest development scenario, the increases in peak flows in all sub-watersheds were greater than $15.00 \%$ in the CLUE-s model. The increases in runoff volumes in all sub-watersheds exceeded $10.00 \%$ in the simultaneously and sequential minimization of MSI and CLUE-s, except in sub-watersheds 6 and 9 for the 35.00\% forest development policy. Moreover, the highest increases in runoff volumes were $20.78 \%$, 
Table 2

Peak flows and runoff volumes of different land-use development strategies under a $15 \%$ forest to built-up land conversion intensity in sub-watersheds.

\begin{tabular}{|c|c|c|c|c|c|c|}
\hline Sub-watershed & Type & Simultaneous MPS 15\% & Sequential MPS 15\% & Simultaneous MSI 15\% & Sequential MSI 15\% & CLUE-s $15 \%$ \\
\hline \multirow[t]{2}{*}{1} & Peak flow & $14.40 \%$ & $14.14 \%$ & $16.71 \%$ & $17.74 \%$ & $20.82 \%$ \\
\hline & Runoff volume & $6.62 \%$ & $6.41 \%$ & $7.58 \%$ & $8.27 \%$ & $9.82 \%$ \\
\hline \multirow[t]{2}{*}{2} & Peak flow & $8.59 \%$ & $8.49 \%$ & $8.22 \%$ & $8.22 \%$ & $8.22 \%$ \\
\hline & Runoff volume & $5.31 \%$ & $5.28 \%$ & $5.16 \%$ & $5.15 \%$ & $5.14 \%$ \\
\hline \multirow[t]{2}{*}{3} & Peak flow & $21.01 \%$ & $20.74 \%$ & $22.34 \%$ & $22.34 \%$ & $17.55 \%$ \\
\hline & Runoff volume & $8.89 \%$ & $8.78 \%$ & $9.48 \%$ & $9.55 \%$ & $7.41 \%$ \\
\hline \multirow[t]{2}{*}{4} & Peak flow & $7.69 \%$ & $7.69 \%$ & $7.69 \%$ & $7.69 \%$ & $12.82 \%$ \\
\hline & Runoff volume & $4.23 \%$ & $4.23 \%$ & $5.26 \%$ & $5.99 \%$ & $9.82 \%$ \\
\hline \multirow[t]{2}{*}{5} & Peak flow & $17.73 \%$ & $17.02 \%$ & $17.73 \%$ & $17.73 \%$ & $22.34 \%$ \\
\hline & Runoff volume & $8.39 \%$ & $7.98 \%$ & $8.26 \%$ & $8.34 \%$ & $10.64 \%$ \\
\hline \multirow[t]{2}{*}{6} & Peak flow & $7.55 \%$ & $7.82 \%$ & $5.93 \%$ & $7.01 \%$ & $6.74 \%$ \\
\hline & Runoff volume & $3.49 \%$ & $3.67 \%$ & $2.89 \%$ & $3.38 \%$ & $3.20 \%$ \\
\hline \multirow[t]{2}{*}{7} & Peak flow & $8.75 \%$ & $8.75 \%$ & $10.00 \%$ & $10.00 \%$ & $16.25 \%$ \\
\hline & Runoff volume & $6.43 \%$ & $6.59 \%$ & $7.36 \%$ & $7.36 \%$ & $12.17 \%$ \\
\hline \multirow[t]{2}{*}{8} & Peak flow & $16.96 \%$ & $18.75 \%$ & $15.18 \%$ & $14.29 \%$ & $19.20 \%$ \\
\hline & Runoff volume & $6.71 \%$ & $7.39 \%$ & $6.04 \%$ & $5.63 \%$ & $7.48 \%$ \\
\hline \multirow[t]{2}{*}{9} & Peak flow & $9.11 \%$ & $9.36 \%$ & $8.62 \%$ & $6.40 \%$ & $6.40 \%$ \\
\hline & Runoff volume & $4.13 \%$ & $4.23 \%$ & $3.79 \%$ & $2.97 \%$ & $2.95 \%$ \\
\hline \multirow[t]{2}{*}{ Entire watershed } & Peak flow & $4.78 \%$ & $4.83 \%$ & $4.61 \%$ & $4.49 \%$ & $4.74 \%$ \\
\hline & Runoff volume & $5.76 \%$ & $5.77 \%$ & $5.73 \%$ & $5.75 \%$ & $6.09 \%$ \\
\hline
\end{tabular}

Note: MPS: mean patch size; MSI: mean shape index. The scenarios with the least increase in peak flow and runoff volume are highlighted in bold font.

Table 3

Peak flows and runoff volumes of different land-use development strategies under a 35\% forest to built-up land conversion intensity in sub-watersheds.

\begin{tabular}{|c|c|c|c|c|c|c|}
\hline Sub-watershed & Type & Simultaneous MPS 35\% & Sequential MPS 35\% & Simultaneous MSI 35\% & Sequential MSI 35\% & CLUE-s 35\% \\
\hline \multirow[t]{2}{*}{1} & Peak flow & $34.70 \%$ & $34.96 \%$ & $34.19 \%$ & $34.70 \%$ & $34.70 \%$ \\
\hline & Runoff volume & $16.95 \%$ & $16.77 \%$ & $16.54 \%$ & $16.85 \%$ & $16.93 \%$ \\
\hline \multirow[t]{2}{*}{2} & Peak flow & $27.15 \%$ & $27.24 \%$ & $27.15 \%$ & $27.24 \%$ & $27.42 \%$ \\
\hline & Runoff volume & $12.24 \%$ & $12.29 \%$ & $12.26 \%$ & $12.26 \%$ & $12.33 \%$ \\
\hline \multirow[t]{2}{*}{3} & Peak flow & $44.41 \%$ & $45.21 \%$ & $45.21 \%$ & $45.48 \%$ & $44.68 \%$ \\
\hline & Runoff volume & $20.23 \%$ & $20.73 \%$ & $20.78 \%$ & $20.92 \%$ & $20.41 \%$ \\
\hline \multirow[t]{2}{*}{4} & Peak flow & $15.38 \%$ & $15.38 \%$ & $12.82 \%$ & $12.82 \%$ & $15.38 \%$ \\
\hline & Runoff volume & $10.56 \%$ & $10.56 \%$ & $10.42 \%$ & $9.82 \%$ & $10.56 \%$ \\
\hline \multirow[t]{2}{*}{5} & Peak flow & $36.88 \%$ & $36.17 \%$ & $35.46 \%$ & $36.17 \%$ & $36.88 \%$ \\
\hline & Runoff volume & $18.55 \%$ & $18.18 \%$ & $17.98 \%$ & $18.21 \%$ & $18.66 \%$ \\
\hline \multirow[t]{2}{*}{6} & Peak flow & $16.17 \%$ & $16.44 \%$ & $16.17 \%$ & $15.90 \%$ & $15.90 \%$ \\
\hline & Runoff volume & $7.74 \%$ & $7.78 \%$ & $7.60 \%$ & $7.54 \%$ & $7.59 \%$ \\
\hline \multirow[t]{2}{*}{7} & Peak flow & $18.75 \%$ & $17.50 \%$ & $18.75 \%$ & $18.75 \%$ & $18.75 \%$ \\
\hline & Runoff volume & $14.91 \%$ & $14.31 \%$ & $14.49 \%$ & $14.49 \%$ & $15.09 \%$ \\
\hline \multirow[t]{2}{*}{8} & Peak flow & $41.52 \%$ & $41.52 \%$ & $41.96 \%$ & $41.96 \%$ & $42.41 \%$ \\
\hline & Runoff volume & $16.30 \%$ & $16.31 \%$ & $16.34 \%$ & $16.32 \%$ & $16.59 \%$ \\
\hline \multirow[t]{2}{*}{9} & Peak flow & $19.70 \%$ & $19.95 \%$ & $19.95 \%$ & $19.70 \%$ & $19.70 \%$ \\
\hline & Runoff volume & $9.29 \%$ & $9.39 \%$ & $9.42 \%$ & $9.37 \%$ & $9.24 \%$ \\
\hline \multirow[t]{2}{*}{ Entire watershed } & Peak flow & $13.25 \%$ & $13.34 \%$ & $13.12 \%$ & $13.25 \%$ & $13.38 \%$ \\
\hline & Runoff volume & $13.35 \%$ & $13.37 \%$ & $13.31 \%$ & $13.36 \%$ & $13.41 \%$ \\
\hline
\end{tabular}

Note: MPS: mean patch size; MSI: mean shape index. The scenarios with the least increase in peak flow and runoff volume are highlighted in bold font.

$20.92 \%$ and $20.41 \%$ in sub-watershed 3 , in the cases of simultaneously maximizing MPS, sequentially maximizing MPS and CLUE-s, respectively.

\section{Discussion}

\subsection{Land-use patterns that result from optimizing landscape metrics and empirical trends}

The advantage of the optimization land-use model is that it provides optimal configurations of land-use based on the objectives and criteria defined by policy makers. Simulated annealing (SA) was applied herein to maximize the MPS and MSI values of the landscape metrics for various forest development scenarios. SA supports the allocation of deforested cells in such a way that the mean patch size is maximized or the mean shape index is minimized as for the most compact patch at the landscape level in the studied watershed. The optimal allocation results demonstrate that SA can be used flexibly to solve the spatial allocation problem, and that it can typically find the optimal solutions to optimal allocation problems (Baskent and Jordan, 2002).
Optimizing for maximum mean forest patch size reduced the number of forest patches and increased average forest patch size. Mean forest patch size increased with land-use intensity, peaking at a $15.00 \%$ deforestation rate before decreasing with further deforestation. At the same time, the increases in shape and fractal indices suggest that the forests became on average more complex in shape. Higher MNN values suggest that they became more dispersed and farther from each other (Fig. 3). The combination of these indices suggests that the less fragmented forests are the result of sacrificing smaller and usually simpler-shaped forests in favor of larger and more complex-shaped forests, resulting in a landscape with more dispersed large patches of complex-shaped forests.

Optimizing to minimize the mean forest patch shape index yielded simpler-shaped forests, but as development intensified, the number of forest patches rapidly increased, their sizes decreased rapidly, and the distance of each to its nearest neighbor decreased before finally increasing (Fig. 3). The mean forest patch shape index was minimal at a deforestation rate of $35.00 \%$, suggesting that the mean forest patch shape index was reduced by creating new, smaller, simpler-shaped forest patches that are closer to other patches, by dissecting the originally larger and more complex- 
shaped forests into smaller but simpler-shaped pieces, resulting in a landscape with more fragmented, simpler-shaped, scattered forest patches.

The OLPSIM results also show that simultaneous optimization can optimize the values of MPS and MSI (maximize values of MPS and minimize values of MSI) more effectively than the sequential optimizing strategy. This result is not surprising since sequential developments are constrained by earlier developmental steps that are unlikely to be optimal for the following steps. That phase-wise consideration of development may not result in the optimal predefined landscape pattern suggests that policymakers should set land-use intensity targets at the onset of land-use planning.

The CLUE-s simulations do not optimize land-use patterns but just allocate land-use as a result of the demand, the suitability of locations for particular uses and conversion rules. The results reveal the probably development of land-use without optimization of the land-use pattern to achieve certain objectives. The advantage of the empirical method is that the whole model procedure is straightforward and easy to reproduce (Overmars et al., 2007). Allowing the landscape to develop according to past development trends CLUE-s has resulted in forest patch sizes and shape complexity values between those in the maximum MPS and minimum MSI scenarios but closer to those of the minimum MSI scenarios. It has also resulted in a landscape with the least forest edge. A review of the parameters that drive the location of built-up lands (Table 1) suggests that these lands tend to be located in areas with gentler slopes and thus lower soil erosion, and closer to other built-up areas. Restated, development in accordance to past development trends has resulted in more clustered developments in flatter terrains. Comparison of landscape patterns from the CLUE-s simulations with the baseline landscape of 1999 (Fig. 4) indicates that as landuse intensified, mean forest patch size decreased and mean forest patch shape became simpler. Hence, as built-up clusters expanded into gentler terrain, the built-up/forest boundaries edged into the forests, resulting in similar edge densities each other but smaller and simpler-shaped forests close to the built-up areas. The landuse pattern simulated by the CLUE-s model has a less regular patch shape than that simulated by the OLPSIM model; it is also less compact and more isolated. This is the realistic result of uncontrolled, autonomous developments, as simulated by the CLUE-s model.

The OLPSIM and the CLUE-s models are top-down models that simulate land-use patterns based on predefined land-use demands, forest removal strategies, spatial land-use policies and non-spatial policies. The key difference between the two models is that CLUE-s simulates land-use patterns without predefining objectives, whereas the OLPSIM model predefines objectives. The CLUE-s model does not provide optimal solutions, but provides plausible developments (Castella and Verburg, 2007). The model results obtained using both methods are useful to determine in which areas the development change in land-use deviates from 'optimal' development patterns.

\subsection{Ecological implications of optimized land-use patterns}

Fragmentation indicates the loss of a certain habitat, a reduction in the size of habitat patches and a weakening of the connections between the patches (Andrén, 1994). In a review of the effects of habitat fragmentation on biodiversity, however, Fahrig (2003) emphasized the distinction between habitat loss versus change in habitat configuration. He noted that most researchers do not distinguish between habitat loss and actual habitat fragmentation, by which he meant the breaking apart of a habitat after controlling for habitat loss. The simulated results in this work reveal the conflict of interests among development strategies that seek to establish various habitat configurations as habitat loss proceeds. For example, minimizing the complexity of the shape of the forest patch can be a desirable objective, because simpler shapes minimize the effect of edges for a given patch size (Dramstad et al., 1996), providing better shelter for edge-sensitive or core species (McGarigal and McComb, 1995). The results of this study, however, reveal that as development expands in an area, the forest patch shape is minimized by the dissection of larger but more complex-shaped patches, which is the equivalent of sacrificing patch size. However, a large forest patch size may also be a desirable objective, because larger patches provide larger and more varied habitats, reducing the probability of extinction due to chance events, increasing thereby the number of species that will be successful after immigration and maintaining a greater diversity of species (MacArthur and Wilson, 1967; Newmark, 1987). However, the results of this study indicate that as development expands in an area, the size of forest patches can be maximized at the expense of smaller, simpler-shaped fragments, inadvertently distancing one patch from another. Such a landscape pattern may be adverse to the maintenance of metapopulations and biodiversity, because immigration among patches decreases as the distance of a patch from a source habitat increases (MacArthur and Wilson, 1967; Hanski, 1998). Patches that are more isolated are less likely to receive immigrants than patches than those that are less isolated. A landscape with more inter-connected habitats is more likely to maintain metapopulations and biodiversity, and has been suggested to be vital to the maintenance of biodiversity in urbanized landscapes (Fernandez-Juricic and Jokimaki, 2001). Therefore, if development pressure unavoidably results in habitat loss, then landscape planners and environmental managers must make choices between desirable landscape configurations.

Past discussions of the SLOSS (single large or several small) choice in the field of refuge design help to face this dilemma by highlighting the importance of the identity of species as opposed to the number of species (Simberloff, 1988). Although an archipelago of small sites may have more species (Simberloff and Abele, 1982; Soule and Simberloff, 1986), large sites may have special importance in maintaining particular species that are sensitive to edge effects (Yahna, 1988). A more sophisticated approach could consider species profiles instead of individual species (Vos et al., 2001). Such species profiles can be applied to group species according to important factors that govern their response to changes in the landscape, such that species that are vulnerable to extinction because of area requirements may be grouped as an "area sensitive group," whereas species that are sensitive to changes in dispersal distance may be grouped in a "distance-sensitive group." Then, the planner/manager will have to which extent to favor patch size, patch shape, or landscape connectivity, given the list of species in each group.

\subsection{Impact of optimal and autonomous land-use patterns on runoff}

Understanding the hydrologic consequences (increased risk and severity of down-stream flooding) of future developments would help planners allocate land for development and/or preservation (Beighley et al., 2003). The results of these simulations suggest that independently of the strategy used, the factor that most strongly influences the peak flow and runoff volume is the percentage of forests that can be converted to built-up lands. All development scenarios that result in a greater peak flow and runoff volume than the 1999 baseline values, and the hydrological outputs increased with the intensity of land-use. The runoff modeling results reveal that the impact of $35.00 \%$ forest development on runoff volume and peak flow is approximately 1.90 and 3.00 times greater, respectively, than the impact of $15.00 \%$ forest development over the entire watershed. Fohrer et al. (2005) noted that absolute changes due to deforestation and the augmentation of grassland and field crops are much smaller than expected. Changes in land-use especially 
affected the peak flow rate. Li et al. (2007) numerically shown that the hydrological response to a change in land coverage is non-linear and exhibits thresholds: the impact on the simulated water yield when the deforestation is less than $50 \%$ is weak and the overgrazing is less $70 \%$ for savanna and $80 \%$ for grassland; however, water yield rapidly increased above the thresholds in their studied watershed.

The hydrological simulations herein suggest that, under the same development intensities, total runoff volumes and flow peaks over the entire watershed were similar across the different scenarios, although the minimum MSI scenarios seemed to have slightly lower total hydrological outputs than the other scenarios. The most visible result, however, is that different land-use scenarios resulted in different degrees to which sub-watersheds contribute to water runoff. Restated, the different land-use strategies differed less in the total hydrological output volume than they did in the distribution of hydrological outputs across sub-watersheds, because the different development scenarios select different deforestation patterns. Since land-use varies in the sub-watersheds, and since stream flows are influenced by land-use influences stream flows, such changes in the distribution of hydrological charges among subwatersheds may have important ecological consequences. More importantly, the results in this study suggest that the amount of vegetated landscape cover affects hydrological outputs more than does landscape configuration. This result is coherent with studies of bird species (McGarigal and McComb, 1995), in which more species were affected by cover than by configuration metrics.

That landscape configuration is less important than landscape composition in determining total hydrological output indicates that the lumped model can distinguish between simulated hydrological components based on land-use demand over the entire watershed; however, this model is less sensitive to simulated land-use scenarios with different spatial land allocation patterns (Lin et al., 2007a). Models that do not consider spatial patterns may not capture the effects of the spatial allocations and the distributions of simulated land-use over the entire watershed for a given land-use demand. Moreover, distributed or semi-distributed hydrological models should be considered in evaluating the impact of landuse patterns on hydrology, particularly under a given land-use demand. In this study, runoff in sub-watersheds was simulated to assess how optimal OLPSIM and CLUE-s land-use patterns influence runoff characteristics and cause changes in the sub-watershed scale. The development of land increases runoff and changes flow peaks, which depend strongly on the spatial allocation of forest developments in the sub-watershed level. Moreover, a higher percentage of forest development corresponds to greater variation in runoff at sub-watershed levels.

\section{Conclusion}

Spatial pattern optimization is a powerful approach for exploring the potential to improve the spatial coherence of land-use functions in a particular area. This study proposed an optimal landuse allocation model OLPSIM that uses SA to optimize predefined landscape metrics. In OLPSIM modeling, SA can successfully solve the spatial allocation problem and locate optimal solutions to landuse allocation problems that meet the objectives of the landscape planner. It also provides decision-makers with optimal development scenarios, so they can set development thresholds in planning land-use in a watershed. The results of maximizing forest patch sizes and minimizing forest patch shapes using the OLPSIM model were compared with those obtained by using the CLUE-s model, which suggests plausible developments and future spatial land-use patterns of watersheds based on previous trends. The simulated results suggest that the three strategies produced very different landscapes in medium intensity scenarios: maximizing for forest patch sizes resulted in the deforestation of small, simple-shaped forest patches, leaving large, complex-shaped forests that were on average relatively far from each other; minimizing forest patch shape resulted in the dissecting of large, complex-shaped forests, to produce smaller, simpler-shaped fragments, and land development based on past trends resulted in the aggregation of urbanized landuse in gentle terrain. Such variations of landscape patterns have different ecological implications and require a more sophisticated approach to landscape planning.

Integrating both land-use models with HEC-HMS, a precipitation-runoff model, provides valuable quantitative information about the effects of land-use intensities and strategies on hydrological output. Also, the effectiveness of the integrated models in studying the spatially explicit hydrologic effect of land-use scenarios at the sub-watershed level, enables them to yield additional information that can help decision-makers evaluate proposed land-use policies. The different land-uses in the sub-watersheds may result in different runoffs. The modeled spatial strategies did not yield significantly different hydrological outputs with low deforestation. Therefore, the spatial solution in this study was not proven to affect hydrology, other than by changing the size of the forest patch such as by the removal of a large amount of forest. However, the fully distributed hydrological model should be used in the future. Obtaining more spatially explicitly, the impacts of urbanization on the sub-basin scale may yield additional information that would help decision-makers evaluate proposed land-use policies (McColl and Aggett, 2007).

\section{Acknowledgement}

The authors would like to thank the National Science Council of the Republic of China, Taiwan, for financially supporting this research under Contract No. 96-2415-H-002-022-MY3.

\section{References}

Andrén, H., 1994. Effects of habitat fragmentation on birds and mammals in landscapes with different proportions of suitable habitats: a review. Oikos 71, 335-366.

Baskent, E.Z., Jordan, G.A., 1995. Characterizing spatial structure of forest landscapes. Can. J. For. Res. 25, 1830-1849.

Baskent, E.Z., Jordan, G.A., 2002. Forest landscape management modeling using simulated annealing. Forest Ecol. Manage. 165, 29-45.

Beighley, R.E., Melack, J.M., Dunne, T., 2003. Impacts of California's climatic regimes and coastal land-use change on streamflow characteristics. J. Am. Water Resour. Assoc. 39, 1419-1433.

Brookes, C.J., 2001. A genetic algorithm for designing optimal patch configurations in GIS. Int. J. Geogr. Inform. Sci. 15, 539-559.

Castella, J.C., Kam, S.P., Quang, D.D., Verburg, P.H., Hoanh, C.T., 2007. Combining topdown and bottom-up modelling approaches of land-use/cover change to support public policies: application to sustainable management of natural resources in northern Vietnam. Land-use Policy 24, 531-545.

Castella, J.C., Verburg, P.H., 2007. Combination of process-oriented and patternoriented models of land-use change in a mountain area of Vietnam. Ecol. Model. 202, 410-420.

Dramstad, W.E., Olson, J.D., Forman, R.T.T., 1996. Landscape Ecology Principles in Landscape Architecture and Land-use Planning. Island Press, Washington DC/New York, USA.

Ducheyne, E.I., Dewulf, R.R., Baets, B.D., 2006. A spatial approach to forestmanagement optimization: linking GIS and multiple objective genetic algorithms. Int. J. Geogr. Inform. Sci. 20, 917-928.

Duh, J.D., Brown, D.G., 2005. Generating prescribed patterns in landscape models. In: Maguire, D.J., Goodchild, M.F., Batty, M.(Eds.), GIS, Spatial Analysis and Modeling. ESRI Press, pp. 423-444.

Elkie, P.C., Rempel, R.S., Carr, A.P., 1999. Patch Analyst User manual: A Tool for Quantifying Landscape Structure. NWST Technical Manual TM-002. Ontario.

Fahrig, L., 2003. Effects of habitat fragmentation on biodiversity. Ann. Rev. Ecol. Evol. 34, 487-515.

Fahrig, L., Merriam, G., 1985. Habitat patch connectivity and population survival. Ecology 66, 1762-1768.

Fernandez-Juricic, E., Jokimaki, J., 2001. A habitat island approach to conserving birds in urban landscapes: case studies from southern and northern Europe. Biodivers. Conserv. 10, 2023-2043.

Floudas, C.A., Paradalos, P.M., 2001. Encyclopedia of Optimization. Kluwer, Dordrecht.

Fohrer, N., Haverkamp, S., Frede, H.G., 2005. Assessment of the effects of land use patterns on hydrologic landscape functions: development of sustain- 
able land use concepts for low mountain range areas. Hydrol. Process. 19, 659-672.

Forman, R.T.T., 1995. Land Mosaic: The Ecology of Landscape and Regions. Cambridge University Press, New York.

Hanski, I., 1998. Metapopulation dynamics. Nature 396, 41-49.

HEC, 2000. Hydrologic Modeling Systems: Technical Reference Manual. US Army Crops of Engineers Hydrologic Engineering Center, Davis, CA.

Hietel, E., Waldhardt, R., Otte, A., 2004. Analyzing land-cover changes in relation to environmental variables in Hesse, Germany. Landscape Ecol. 19, 473-489.

Hof, J., Flather, C., 2007. Optimization of landscape pattern. In: Wu, J., Hobbs, R.J. (Eds.), Key Topics in Landscape Ecology. Cambridge University, New York, USA.

Holzkämper, A., Lausch, A., Seppelt, R., 2006. Optimizing landscape configuration to enhance habitat suitability for species with contrasting habitat requirements. Ecol. Model. 198, 277-292.

Jongman, R.H.G., 1999. Landscape ecology in land-use planning. In: Wiens, J.A., Moss, M.R. (Eds.), Issue in Landscape Ecology. International Association for Landscape Ecology, Guelph, Ontario, pp. 112-118.

Knebl, M.R., Yang, Z.L., Hutchision, K., Maidment, D.R., 2005. Regional scale flood using NEXRAD rainfall, GIS, and HEC-HMS/RAS: a case study for the San Antonio River Basin Summer 2002 storm event. Environ. Manage. 75, 325-336.

Koomen, E., Stillwell, J., 2007. Modelling land-use change. In: Koomen, E., Stillwell, J., Bakema, A., Scholten, H.J. (Eds.), Modeling Land-use Change: Progress and Applications. Springer, Dordrecht, Netherlands, pp. 146-166.

Laurance, W.F., 1991. Edges effects in tropical forest fragments: application of a model for the design of nature reserves. Biol. Conserv. 57, 205-219.

Leitão, A.B., Miller, J., Ahern, J., McGarigal, K., 2006. Measuring Landscapes: A Planner's Handbook. Island Press, Washington DC, USA.

Lesschen, J.P., Kok, K., Verburg, P.H., Cammeraat, L.H., 2007. Identification of vulnerable areas for gully erosion under different scenarios of land abandonment in Southeast Spain. Catena 71, 110-121.

Li, K.Y., Coe, M.T., Ramankutty, N.R., De Jong, R., 2007. Modeling the hydrological impact of land-use change in West Africa. J. Hydrol. 337, 258-268.

Lin, Y.P., Hong, N.M., Wu, P.J., Lin, C.J., 2007a. Modeling and assessing land-use and hydrological processes to future land-use and climate change scenarios in watershed land-use planning. Environ. Geol. 53, 623-634.

Lin, Y.P., Hong, N.M., Wu, P.J., Wu, C.F., Verburg, P.H., 2007b. Impacts of land-use change scenarios on hydrology and land-use patterns in the $\mathrm{Wu}$-Tu watershed in Northern Taiwan. Landscape Urban Plan. 80, 111-126.

Loonen, W., Heuberger, P., Kuijpers-Lide, M., 2007. Spatial optimization in land-use allocation problems. In: Koomen, E., Stillwell, J., Bakema, A., Scholten, H. (Eds.), Modelling Land-use Change. Springer, Netherlands, pp. 147-165.

MacArthur, R.H., Wilson, E.O., 1967. The Theory of Island Biogeography. Princeton University Press, Princeton.

Mandal, S.K., 2007. Sustainable land-use and water management in mountain ecosystems. In: Koomen, E., Stillwell, J., Bakema, A., Scholten, H.J. (Eds.), Modeling Land-use Change: Progress and Applications. Springer, Dordrecht, Netherlands, pp. 181-198.

McColl, C., Aggett, G., 2007. Land-use forecasting and hydrologic model integration for improved land-use decision support. Environ. Manage. 84, 494-512.

McGarigal, K., Marks, B.J., 1995. FRAGSTATS: spatial pattern analysis program for quantifying landscape structure. USDS For. Sev. Gen. Tec. Re, PNW-351.

McGarigal, K., McComb, W.C., 1995. Relationships between landscape structure and breeding birds in the Oregon Coast Range. Ecol. Monogr. 65, 235-260.

Newmark, W.D., 1987. A land-bridge island perspective on mammalian extinctions in western North American parks. Nature 325, 430-432.

Öhman, K., Lämås, T., 2005. Reducing forest fragmentation in long-term forest planning by using the shape index. Forest Ecol. Manage. 212, 346-357.

Overmars, K.P., Verburg, P.H., Veldkamp, T., 2007. Comparison of a deductive and an inductive approach to specify land suitability in a spatially explicit land-use model. Land-use Policy 24, 584-599.

Poiani, K.A., Merrill, M.D., Chapman, K.A., 2002. Identifying conservation-priority areas in a fragmented Minnesota landscape based on the umbrella species concept and selection of large patches of natural vegetation. Conserv. Biol. 15 513-522.
Probst, J.R., Weinrich, J., 1993. Relating Kirtlands warbler population to changing landscape composition and structure. Landscape Ecol. 9, 257-271.

Robinson, G.R., Holt, R.D., Gaines, M.S., Hamburg, S.P., Johnson, M.L., Fitch, H.S., Martinko, E.A., 1992. Diverse and contrasting effects of habitat fragmentation. Science 257, 524-526.

Selman, P., Doar, N., 1992. An investigation of the potential for landscape ecology to act as a basis for rural land-use plans. Environ. Manage. 35, 281-289.

Seppelt, R., Voinov, A., 2002. Optimization methodology for land-use patterns using spatially explicit landscape models. Ecol. Model. 151, 125-142.

Simberloff, D., 1988. The contribution of population and community biology to conservation science. Ann. Rev. Ecol. Syst. 19, 473-511.

Simberloff, D., Abele, L.G., 1982. Refuge design and island biogeographic theory: effects of fragmentation. Am. Nat. 120, 41-50.

Soule, M.E., Simberloff, D., 1986. What do genetics and ecology tell us about the design of nature reserves? Biol. Conserv. 35, 19-40.

Turner, M.G., Gardner, R.H., O’Neill, R.V., 2001. Landscape Ecology in Theory and Practice: Pattern and Process. Springer-Verlag, New York, USA.

Verburg, P.H., Overmars, K.P., Huigen, M.G.A., de Groot, W.T., Veldkamp, A., 2006. Analysis of the effects of land-use change on protected areas in the Philippines. Appl. Geogr. 26, 153-173.

Verburg, P.H., Veldkamp, A., 2005. Editorial: spatial modeling to explore land-use dynamics. Int. J. Geogr. Inform. Sci. 19, 99-102.

Villard, M.-A., Trzcinski, M.K., Merriam, G., 1999. Fragmentation effects on forest birds: relative influence of woodland cover and configuration on landscape occupancy. Conserv. Biol. 13, 774-783.

Vos, C.C., Verboom, J., Opdam, P.F.M., Ter Braak, C.J.F., 2001. Towards ecologically scaled landscape indices. Am. Nat. 157, 24-51.

Westphal, M.I., Field, S.A., Possingham, H.P., 2007. Optimizing landscape configuration: a case study of woofland birds in the Mount Lofty Ranges, South Australia. Landscape Urban Plan. 81, 56-66.

Wu, J., Hobbs, R., 2002. Key issues and research priorities in landscape ecology: an idiosyncratic synthesis. Landscape Ecol. 17, 355-365.

Yahna, R.H., 1988. Changes in wildlife communities near edges. Conserv. Biol. 2 , 333-339.

Zander, P., Kächele, H., 1999. Modelling multiple objectives of and use for sustainable development. Agric. Syst. 59, 311-325

Yu-Pin Lin is a professor in the Department of Bioenvironmental Systems Engineering at National Taiwan University in Taiwan. He received his Ph.D. degree from the Georgia Institute of Technology in the United States. Professor Lin studies the applications and developments of spatial statistical techniques, landscape ecological approaches, land-use modeling, optimal monitoring sampling design, and freshwater biological monitoring and assessment.

Peter Verburg is a senior researcher at the Department of Environmental Sciences at Wageningen University, The Netherlands. He has extensive experience with the spatial analysis and modeling of agro-ecosystems, land-use, urban systems and landscape pattern. Peter Verburg has participated in a number of interdisciplinary (IGBP/IHDP) LUCC related research projects in different parts of the world including China, the Philippines and Europe. Currently he is project coordinator of the CLUE model (http://www.cluemodel.nl), a well-established, spatially explicit methodology for simulating land-use change with many national and internationa counterparts and applications.

Chi-Ru Chang is an associate professor in the Department of Landscape Architecture at Chinese Culture University. Dr. Chang studies landscape ecology, ecological model and environmental management.

Horng-Yng Chen is a graduate student in the Department of Bioenvironmental Systems Engineering at National Taiwan University in Taiwan. She studies integrations of land-use and hydrological modeling.

Min-Hua Chen holds his M.S. degree from the Department of Bioenvironmental Systems Engineering at National Taiwan University in Taiwan. 